LOPES, André Camargo; BARBOSA, Carlos Alberto Sampaio. Fotografias na praça: a produção e os usos das fotografias de atestação nos ex-votos de romeiros em Aparecida (SP) entre as décadas de 1940-1980. Domínios da imagem, v. 13, n. 25, p.4064, jul./dez. 2019.

Recebido em 11/11/2017 e aprovado em: 30/01/2020

\title{
FOTOGRAFIAS NA PRAÇA: A PRODUÇÃO E OS USOS DAS FOTOGRAFIAS DE ATESTAÇÃO NOS EX-VOTOS DE ROMEIROS EM APARECIDA (SP) ENTRE AS DÉCADAS DE 1940-1980
}

\section{PHOTOS IN THE SQUARE: \\ THE PRODUCTION AND USES OF ATTESTATION PHOTOGRAPHS IN THE EX-VOWS OF PILGRIMS IN APARECIDA (SP) BETWEEN THE DECADES OF 1940-1980}

\author{
André Camargo Lopes ${ }^{1}$ \\ Carlos Alberto Sampaio Barbosa ${ }^{2}$
}

\begin{abstract}
Resumo: Este trabalho se propõe a analisar um conjunto de imagens fotográficas coletadas em acervos de famílias de moradores da região norte do Município de Londrina (PR) entre os anos de 2009 e 2013, cujo tema remete as poses retratadas no Santuário Nacional de Aparecida (SP) entre os anos de 1940 e 1980. A análise presente neste artigo concentra-se na rede produtora das imagens, sua circulação e a produção de sentidos. Delimitada em um recorte histórico que objetiva examinar tanto as redes como os indivíduos responsáveis pela construção e manutenção do olhar fotográfico sobre os espaços de fé no Santuário de Aparecida (SP).
\end{abstract}

Palavras chave: Fotografia, catolicismo, Aparecida, romeiro.

\begin{abstract}
This work proposes to analyze a set of photographic images collected in collections of families of residents of the northern region of the city of Londrina (PR) between the years 2009 and 2013, whose theme refers to the poses portrayed in the National Sanctuary of Aparecida (SP) between the years 1940 and 1980. The analysis in this article focuses on the network that produces images, their circulation, and the production

\footnotetext{
I Doutor em História e Sociedade pela UNESP/Assis. Professor da Rede Estadual de Ensino Básico do Estado do Paraná. Atua também como pesquisador educacional no mercado editorial. Como acadêmico desenvolve pesquisas na área de estudos culturais e cultura visual, abordando temas como religiosidade popular, fotografia e iconografia vernacular, arte e ensino de arte, Educação e formação de professores.

2 Doutor em História Social pela Universidade de São Paulo, e pós-doutorado no Instituto de História do Centro de Ciências Humanas e Sociais do Consejo Superior de Investigaciones Científicas em Madri, Espanha. Professor de História das Américas vinculado ao Programa de Pós-graduação em História da UNESP/Assis. Autor dos livros: Revolução Mexicana; A Fotografia a Serviço de Clio: uma interpretação da história visual da Revolução Mexicana (1900-1940); além de diversos artigos em revistas científicas.
} 
LOPES, André Camargo; BARBOSA, Carlos Alberto Sampaio. Fotografias na praça: a produção e os usos das fotografias de atestação nos ex-votos de romeiros em Aparecida (SP) entre as décadas de 1940-1980. Domínios da imagem, v. 13, n. 25, p.4064, jul./dez. 2019.

of meanings. It is delimited in a historical section that aims to examine both the networks and the individuals responsible for the construction and maintenance of the photographic view on the spaces of faith in the Aparecida Sanctuary (SP).

Keywords: Photography, Catholicism, Aparecida, romeiro.

Este texto se propõe analisar um conjunto de fotografias registradas por fotógrafos Lambe-Lambe no Santuário de Aparecida, em São Paulo. Como objeto de estudo histórico, estabelece-se um recorte temporal entre as décadas de 1940 a 1980, período, no qual segundo os relatos obtidos junto aos fotógrafos remanescentes, corresponde ao espaço de tempo da popularização e barateamento do serviço ao seu declínio diante da popularização da câmeras compactas. Como elemento de análise, procura-se apresentar através destas imagens as relações estabelecidas pelos devotos no espaço do Santuário de Aparecida (SP), e a apropriação dos serviços religiosos nele prestados (dentre eles, a fotografia). Suas formas de apropriação, reorientando os símbolos do local em suas buscas pessoais, assim como se construindo como presentes e "pertencentes" ao espaço. Estabelecendo um perfil de relações especificas na composição e produção destas imagens que podem ser assim definidas:

- Fotógrafo/romeiro

- Romeiro/santa

- Romeiro/fotógrafo/imaginário social

São essas relações de trocas os elementos centrais na análise do imaginário social produtor dessas fotografias. Sendo assim, essa relação entre a intenção do voto, a memória e o objeto-imagem, é abordado a partir de seu processo de produção, circulação e armazenamento. Expondo neste, elementos de sua condição indiciária reforçada pela presença dos indivíduos em seus corpos. Fotografias são artefatos, objetos de uma realidade concreta que permeia a vida íntima de seus proprietários, revelando agudamente suas personalidades e os hábitos 
LOPES, André Camargo; BARBOSA, Carlos Alberto Sampaio. Fotografias na praça: a produção e os usos das fotografias de atestação nos ex-votos de romeiros em Aparecida (SP) entre as décadas de 1940-1980. Domínios da imagem, v. 13, n. 25, p.4064, jul./dez. 2019.

do grupo familial e social ao qual pertencem. Tomada tal perspectiva sobre a natureza do objeto nos estudos históricos e a condição da imagem também como objeto, Meneses (2005, p. 50), afirma que "(...) as imagens não são puros conteúdos em levitação ou meras abstrações, mas antes de mais nada, constituem coisas materiais, objetos físicos coisas materiais".

Deste modo, a reflexão sobre os usos da fotografia em meios populares, sua produção, comercialização e circulação. Pode ser problematizada por alguns questionamentos: O que são as fotografias para esses indivíduos? Como essas acionam a memória? E a partir de quais relações concretas essas se consolidam?

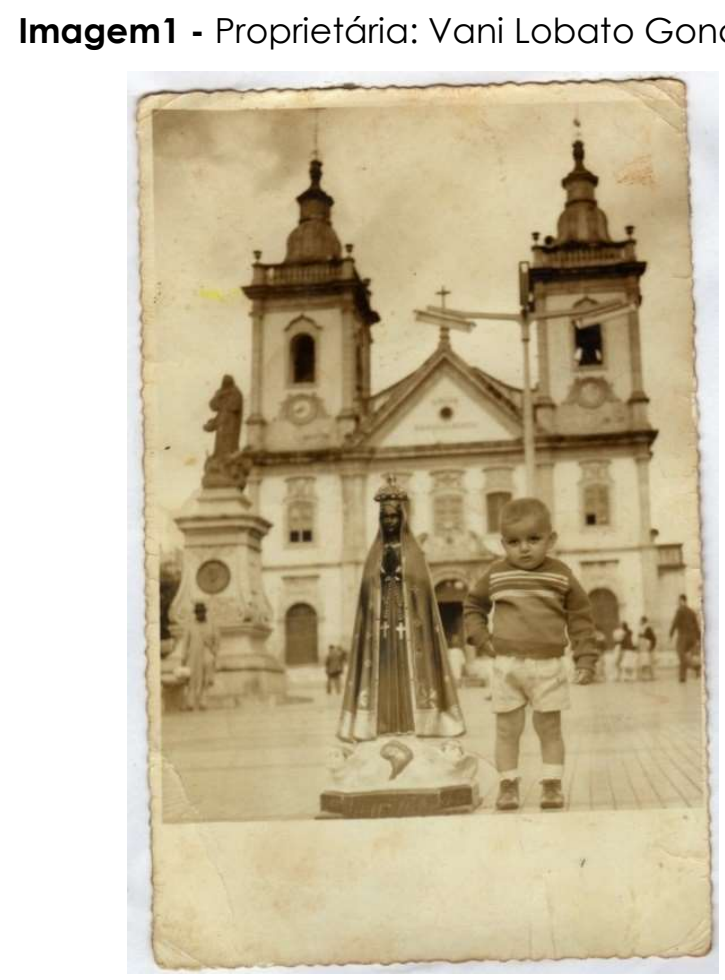

Acervo: André Camargo Lopes/ projeto Clube da Fotografia

Os questionamentos acima têm na análise da fotografia 1 alguns elementos que possibilitam sua melhor compreensão. A imagem disponibilizada, trata da digitalização de uma fotografia em papel 
LOPES, André Camargo; BARBOSA, Carlos Alberto Sampaio. Fotografias na praça: a produção e os usos das fotografias de atestação nos ex-votos de romeiros em Aparecida (SP) entre as décadas de 1940-1980. Domínios da imagem, v. 13, n. 25, p.4064, jul./dez. 2019.

brilhoso e espesso, de dimensões $15 \times 9,6$ centímetros, composta em seu primeiro plano por uma pequena criança que pose ao lado da Santa: uma atitude simples, porém, sustentada em um complexo universo material e simbólico. A fotografia foi realizada em 1963, e pertence ao acervo pessoal de Vani Lobato Gonçalves (cedida para a digitalização juntamente com outras fotografias em março de 2009).

Situando os personagens à narrativa pretendida na composição, tem-se no primeiro plano, Hélio Lobato, uma criança recém-curada da Bronquite, menor do que a estátua de Nossa Senhora Aparecida, que posou como atestação da promessa cumprida. No caso, "feita3" por sua mãe Dolores Lobato durante a viagem com a criança que seria a paga pelo milagre.

Essa e tantas outras histórias forma cedidas para digitalização por diversos acervos particulares de famílias de moradores da região norte de Londrina (PR). As imagens em si, foram coletadas entre os anos de 2009 e 2013. Tal material possibilitou uma análise balizada a partir da concepção das fotografias enquanto uma mercadoria de lembrança ou ex-voto explorada economicamente pelos fotógrafos ambulantes nos marcos de concentração de romeiros, especificamente as poses produzidas na Praça Nossa Senhora Aparecida. Uma rede produtora de uma memória sobre o espaço sagrado presente no imaginário religioso popular.

Essas "Fotografias de Aparecida", que revelam a dimensão de um imagético devocional, são narrativas que em sua composição também expõem elementos de um imaginário social, um discurso com e sobre o sagrado, manifesto de forma física neste universo cultural. Homens, mulheres, crianças, representados em instantâneos que atestam as suas

\footnotetext{
${ }_{3}^{3}$ Neste caso a expressão remete à compra da imagem, ou encomenda do serviço.
} 
LOPES, André Camargo; BARBOSA, Carlos Alberto Sampaio. Fotografias na praça: a produção e os usos das fotografias de atestação nos ex-votos de romeiros em Aparecida (SP) entre as décadas de 1940-1980. Domínios da imagem, v. 13, n. 25, p.4064, jul./dez. 2019.

próprias vivências da fé, de uma devoção que, em sua prática, é espontânea e não litúrgica.

Com motivos diversificados, a produção dessas imagens fotográficas descortina aspectos do universo devocional católico brasileiro. Extrapolando a rotina doméstica, essas imagens de devotos, que buscam nas fotografias, compor a cena negociada do milagre, 0 instantâneo da salvação, tal como afirma Segala (2000, p. 172.) "(...) ao ar livre, à luz do sol vem aparecer a imagem deles com a santa, em gesso ou em tela, reatualizando, simbolicamente, pela técnica moderna a aparição da Virgem nas águas do rio, são contratos de fé".

E essa construção de sentido do sagrado aponta para dois princípios determinantes no imaginário religioso que nutre o catolicismo popular: para o devoto: primeiro, há um lugar consagrado, em que o fenômeno religioso é mais intenso - um espaço estruturado nas narrativas de milagres. O outro aspecto está relacionado à demanda do milagre a promessa e a capacidade do santo em promover os milagres.

\section{As "Fotografias de Aparecida"}

O Santuário de Aparecida, no estado de São Paulo, é um grande polo do turismo religioso brasileiro para o qual se deslocam anualmente milhares de pessoas em busca de graças e interseções, ou como pagamento de promessa, muitos em romaria. Por causa deste fluxo contínuo de romeiros se desenvolveu um campo comercial de fé. 
LOPES, André Camargo; BARBOSA, Carlos Alberto Sampaio. Fotografias na praça: a produção e os usos das fotografias de atestação nos ex-votos de romeiros em Aparecida (SP) entre as décadas de 1940-1980. Domínios da imagem, v. 13, n. 25, p.4064, jul./dez. 2019.

Imagem 2 - A Praça Nossa Senhora Aparecida em Aparecida (SP), fins da década de 1970. Catalogação: João Bosco Garcia

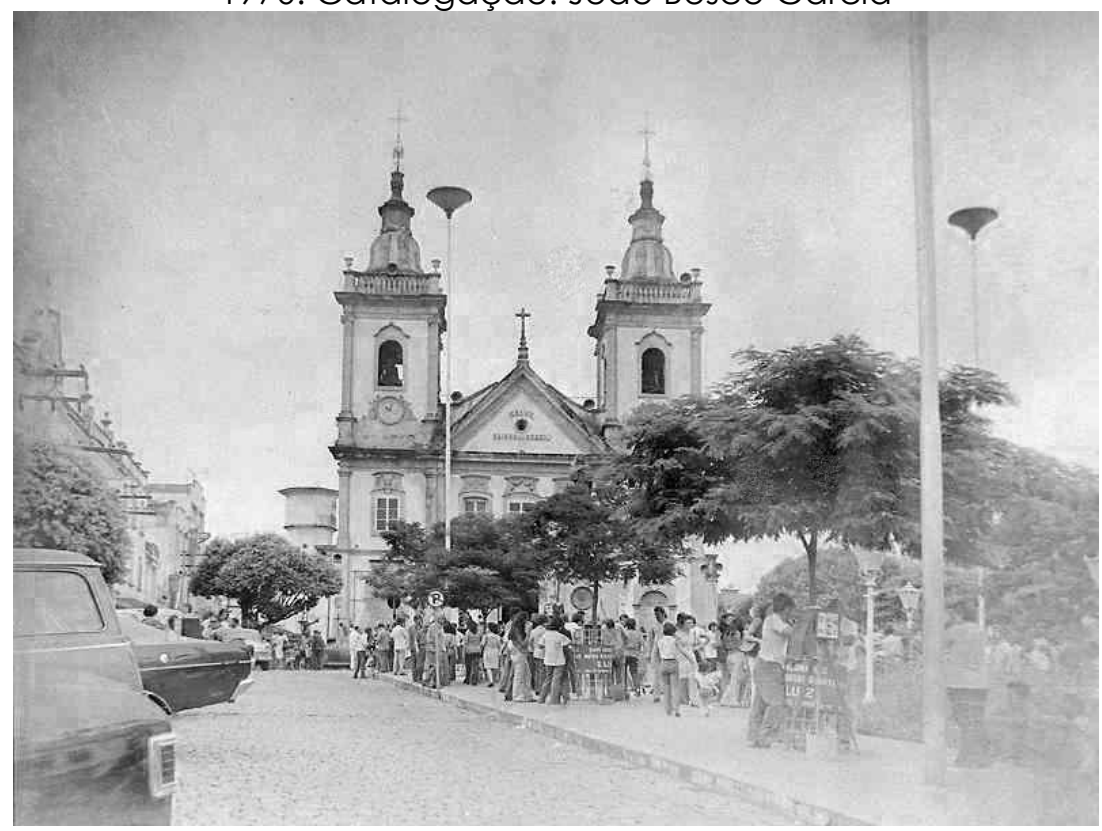

Acervo: Jornal Tranca e Gamela/Aparecida (SP)

E nesse campo, o mercado de fotografias instantâneas, os fotógrafos ambulantes a ocuparem as áreas de aglomeração (os principais pontos do turismo religioso, como podemos ver na imagem 2) com suas grandes máquinas-laboratórios las tradicionais "lambelambe"), sobressaíram-se como os grandes produtores da visualidade relativa a estes romeiros que transitaram entre a Praça Nossa Senhora Aparecida e a antiga igreja-matriz.

Este mercado fotográfico, foi constatado no estudo de Lygia Segala (2000), no qual a autora afirma que esses compunham um quadro organizacional que representa uma área complexa de estudos, visto a presença dos fotógrafos autônomos e ambulantes que povoaram a Praça diante da antiga matriz, e os outros espaços turísticos da cidade, ao longo da segunda metade do século XX, como pela disputa de espaço com os laboratórios e estúdios instalando-se em um consistente nicho comercial durante este mesmo período. Assim como também o do 
LOPES, André Camargo; BARBOSA, Carlos Alberto Sampaio. Fotografias na praça: a produção e os usos das fotografias de atestação nos ex-votos de romeiros em Aparecida (SP) entre as décadas de 1940-1980. Domínios da imagem, v. 13, n. 25, p.4064, jul./dez. 2019.

choque e gradual enfraquecimento da presença destes profissionais frente à expansão das novas tecnologias de registro imagético com o consequente barateamento das máquinas fotográficas que ampliaram o acesso popular à produção de fotografia.

A imbricação desses aspectos no campo de disputa por relevância desvela as transformações nas técnicas de trabalho, nas tecnologias aplicadas, na ação humana sobre o próprio espaço, e na relação dos profissionais com os romeiros.

E é nesse contexto em que ocorre a produção e os usos da imagem por fotógrafos e romeiros que atuaram (e atuam) nos espaços da cidade. Deste modo, pretendemos abordá-las enquanto elementos componentes de uma rede estruturadora de um olhar-se no, e sobre o espaço, que, simultaneamente, é resultante de um condicionamento social relativo a estas representações imagéticas, e que revela as formas de relacionamento e de experiência individual dentro do espaço consagrado.

Nessa perspectiva, a fotografia enquanto documento histórico também assume a condição de elemento de manutenção e adequação dos espaços de fé no imaginário popular ${ }^{4}$. Ou seja, como abordagem de um universo cultural que se estrutura por meio das práticas e relações destes agentes no espaço de romaria, tem-se na imagem a manifestação de uma seletividade dos agentes referente à determinação dos espaços de fé. Pensada como resultado da condição imaginada entre fotógrafos e fotografados, esta ação seria uma projeção selecionada e definida por ambos do que é legítimo na construção da lembrança das práticas sociais em que atuam.

\footnotetext{
4 É nesse aspecto estruturador que abordo o conceito de imaginário social, que corresponde à ação desses indivíduos (isolada ou coletivamente) sobre um conjunto de imagens verbais e visuais geradas em suas vivências cotidianas, ou seja, a sua construção social, por meio de uma relação consigo mesmo, com grupos próximos ou externos, em uma conjuntura.
} 
LOPES, André Camargo; BARBOSA, Carlos Alberto Sampaio. Fotografias na praça: a produção e os usos das fotografias de atestação nos ex-votos de romeiros em Aparecida (SP) entre as décadas de 1940-1980. Domínios da imagem, v. 13, n. 25, p.4064, jul./dez. 2019.

Outro aspecto resultante desse campo de relações é a configuração simbólica dos elementos estruturadores da imagem fotográfica. Como afirma Martins (2009), as fotografias são, nesse tipo de representação, elementos vivos de uso substitutivo, ou seja, presentificam uma ação de troca, entre o ser e a sua imagem captada, na relação com o sagrado. São leituras do ato de fé mediadas (ou não) pelo fotógrafo, porém constituem-se em mais do que um mero registro de memória visual do evento, são algo sagrado, e quando usadas como exvotos, legitimam a fé do romeiro confiada ao santo. Visualmente, a repetição do padrão compositivo constitui um perfil de imagem classificada neste trabalho como "fotografia de atestação"5.

Distintas das fotografias de batismo e de primeira comunhão que correspondem a registros de ritos de passagem na vida religiosa, as "Fotografias de Aparecida" (SP) - assim como as realizadas em outros santuários católicos -, assumem o caráter de uma prova material do contrato cumprido. A materialização visual da promessa. A compreensão de seu sentido se dá por meio do filtro cultural-religioso que as sustenta: nas práticas sociais e culturais de construção do olhar do romeiro sobre o espaço sagrado com suas possíveis conotações, assim como nos padrões de representação que se consolidaram dentro desse imaginário religioso. Percebidas assim, tais imagens revelam também, as transformações nas redes de sociabilidade que as produzem, levantando aos seguintes questionamentos em sua abordagem:

\footnotetext{
5 Incorporadas à pesquisa, essas imagens tendem a aflorar a sua natureza devocional quando confrontadas com os relatos de seus proprietários e dos fotógrafos produtores das imagens. Seus usos correspondem a um índice principal de classificação: o número de imagens produzidas; a lembrança fotográfica que volta como registrado da viagem; o compartilhamento com familiares e amigos; e, a imagem depositada na Sala de Promessas.
} 
LOPES, André Camargo; BARBOSA, Carlos Alberto Sampaio. Fotografias na praça: a produção e os usos das fotografias de atestação nos ex-votos de romeiros em Aparecida (SP) entre as décadas de 1940-1980. Domínios da imagem, v. 13, n. 25, p.4064, jul./dez. 2019.

- Sobre os códigos visuais que corroboram e dão materialidade à fé do agente analisado (o romeiro), procurando evidenciar seus padrões de representação que convertem a imagem em título de legitimidade de fé em sua lógica social;

- Sobre a significação do ato de afirmação da identidade religiosa associado ao espaço de fé, ou seja, o que o ser romeiro e estar em Aparecida representam para estes agentes, e neste sentido, "ler" a romaria dentro das tradições familiares expressas nas narrativas imagéticas que constroem e legitimam este universo simbólico;

- E sobre as transformações do olhar fotográfico sobre o espaço sagrado e as formas de manutenção do ato devocional, assim como as prováveis reconfigurações no mercado de produção deste bem simbólico.

\section{A autorrepresentação e a tradição de uma imaginária devocional}

As "Fotografias de Aparecida" são as imagens produzidas no (e para o) Santuário que, em seu corpus imagético, constituem uma visualidade muito peculiar da devoção popular, revelando aspectos do comportamento religioso do romeiro, assim como continuidades e rupturas nas relações estruturantes das práticas no catolicismo popular brasileiro, de uma visão do corpo e de sua representação.

Tal perspectiva assinala, no âmbito da relação devocional, que os agentes produtores do catolicismo popular não excluem, em seu itinerário de fé, as práticas oficiais. É uma hibridização entre as instâncias deste universo simbólico baseado nas práticas religiosas pautadas em orações, procissões e romarias, e que revela nestes ritos de fé popular tanto o caráter individual ou familiar quanto o coletivo e social. 
LOPES, André Camargo; BARBOSA, Carlos Alberto Sampaio. Fotografias na praça: a produção e os usos das fotografias de atestação nos ex-votos de romeiros em Aparecida (SP) entre as décadas de 1940-1980. Domínios da imagem, v. 13, n. 25, p.4064, jul./dez. 2019.

Imagem 3 - Imagem 4 - Imagem 5 - (meados da década de 1970) - proprietária: Maria aparecida Barbosa; (aprox. final da década de 1960) - proprietário: Família Caovilla; (aprox. década de 1950) - proprietário: Maria de Lourdes Franciscão.
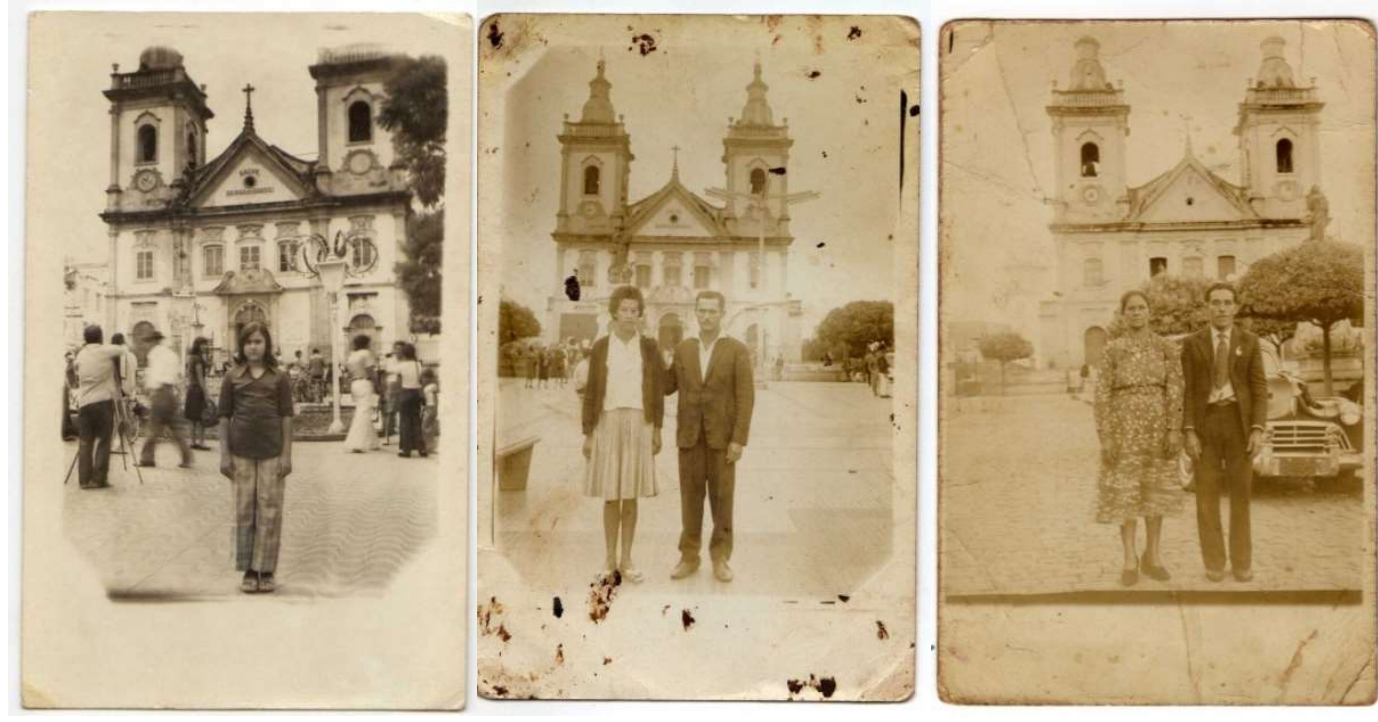

Acervo: André Camargo Lopes/ projeto Clube da Fotografia

A presença significativa desse repertório imagético em quase todas as famílias participantes da catalogação e da pesquisa revelou o papel importante das imagens de "atestação", como pode ser verificado no conjunto de imagens acima. Poses frontalizadas, corpos inteiros e comportados, ao fundo a igreja como afirmação do lugar. Consideramos que essas cumprem o papel de avalizarem a relação entre santo e devoto, motivadora do movimento de romaria aos santuários católicos brasileiros.

Como materialização de um imaginário católico popular essas imagens também revelam intenções em uma prática que se constitui por meio da relação íntima estabelecida daquele que pede (o devoto), que solicita uma intercessão, e que tendo o pedido alcançado (a graça), promove rezas em louvor ao seu benfeitor (o santo). Assim, o corpo físico registrado no papel atesta a identidade do devoto.

Desse modo, os devotos unem-se aos santos em pactos de fé que se materializam em forma de devoção, e, nessa prática, a fotografia corresponde à parcela final da relação. A ligação se estreita pelas trocas 
LOPES, André Camargo; BARBOSA, Carlos Alberto Sampaio. Fotografias na praça: a produção e os usos das fotografias de atestação nos ex-votos de romeiros em Aparecida (SP) entre as décadas de 1940-1980. Domínios da imagem, v. 13, n. 25, p.4064, jul./dez. 2019.

simbólicas e sociais repetidas a cada nova promessa, reza e romaria cumprida, em um ciclo de dar - receber - retribuir.

A imagem 6 desvela essa ação de troca em sua condição material, o grupo de romeiros se faz retratar, não apenas de corpo presente, mas em sua intenção, nas posturas e nos objetos (velas) que sustentam.

Imagem 6 - Grupo de romeiros na Praça Nossa Senhora Aparecida em Aparecida (SP) - s/d. Catalogação: João Bosco Garcia

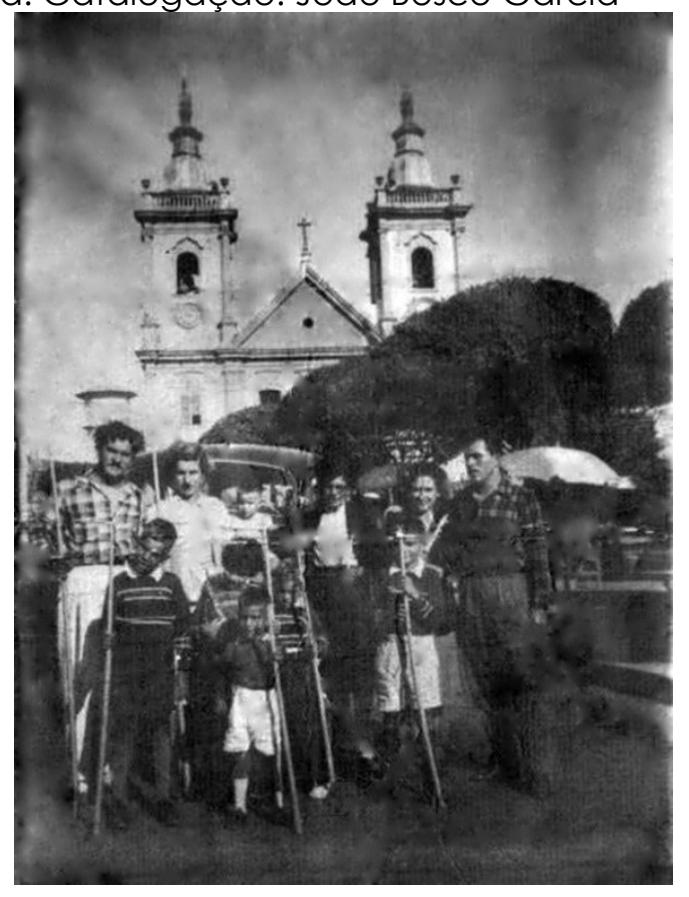

Acervo: Jornal Tranca e Gamela/Aparecida (SP)

É a comprovação da promessa paga. As velas e os devotos são registrados na Praça Nossa Senhora Aparecida (sem data específica) tendo como fundo a antiga Baślica. A promessa cumprida reforça da relação entre a santa e o devoto. Esta leitura reitera o que Menezes (2004), em seus estudos sobre a dinâmica do sagrado no convento de Santo Antônio no Rio de Janeiro, definiu como a constituição da representatividade do santo junto ao público de devotos, ou seja, os 
LOPES, André Camargo; BARBOSA, Carlos Alberto Sampaio. Fotografias na praça: a produção e os usos das fotografias de atestação nos ex-votos de romeiros em Aparecida (SP) entre as décadas de 1940-1980. Domínios da imagem, v. 13, n. 25, p.4064, jul./dez. 2019.

vínculos se reforçam pelos milagres que possam realizar e do tipo de causa que venham a atender.

Essas imagens fotográficas indicam uma leitura da relação que o devoto mantém com os espaços do sagrado no Santuário também nos seguintes aspectos: notas de agradecimento no verso das fotografias; crianças vestidas de branco; retratos de famílias inteiras a frente da "Igreja Velha", e de crianças ao lado de pequenas estátuas da Santa.

Estas e outras imagens revelam práticas devocionais e que também expõe a condição do romeiro de viajante por um circuito de turismo-religioso, em que a fé se consolida em um souvenir, uma lembrança de estadia. A peregrinação ao Santuário mescla compreensões e práticas distintas, veiculadas pelas categorias de pessoas e grupos que neste espaço expressam suas intenções e experiências religiosas, porém focadas na manutenção da fé enquanto fenômeno social:

Para os romeiros, Milagres e seus lugares sagrados surgiram como resultado de uma sucessão de acontecimentos miraculosos que escapam à esfera do controle humano. Nesse sentido, o milagre tornava-se a afirmação do sagrado, a resposta de Deus aos rogos dos necessitados e, imbricando mito e história, explicava a origem do santuário, sustentando a sacralização dos espaços como também a construção da identidade local e de sua urbanidade e ampliação do universo religioso dos romeiros que para lá peregrinavam. (JESUS, 2006, p. 87)

As imagens e testemunhos ${ }^{6}$ do romeiro retratado indicam 0 objetivo de quitação da promessa. E, neste sentido, estabelece uma

6 A partir das discussões de Jesus (2006), comparadas ao levantamento fotográfico delimitado entre os anos de 1940 e 1980, e às entrevistas com os proprietários de imagens que realizamos, este pagamento se modificava: muitos prometiam levar seus filhos, todos juntos ou um a cada ano; outros tantos deviam seguir apenas com suas esposas ou depositarem seus ex-votos; e alguns apenas acendiam velas no Cruzeiro. A 
LOPES, André Camargo; BARBOSA, Carlos Alberto Sampaio. Fotografias na praça: a produção e os usos das fotografias de atestação nos ex-votos de romeiros em Aparecida (SP) entre as décadas de 1940-1980. Domínios da imagem, v. 13, n. 25, p.4064, jul./dez. 2019.

ligação entre o mundo humano e o divino. Na sutileza da informação revelada pela composição fotográfica, nos locais que a compõem e nas muitas notas de verso ratificando sua intenção, um agente produtor da própria fé se consolida a olhar-se no espaço sagrado. As razões para a realização da promessa se revelam, localizando nos lugares registrados o contrato firmado entre santo e devoto, transformando a imagem na prova material do pagamento prometido ao santo. Desse modo as fotografias, assumem em sua origem nesta rede de trocas, a condição de "documentos de nascença", tal como observa Ulpiano Meneses (1997), ao ponto de afirmar que que desde sua origem, essas fotografias, como objetos, são projetados para registrarem informações. Todavia, os objetos nada mais fazem que reafirmem os indivíduos que o produzem em uma rede de relações sociais.

Como marco da memória, no espaço doméstico, a fotografia atua como uma autonarrativa destes agentes e de suas respectivas presenças dentro de um processo seletivo direcionado por suas próprias intenções (no momento fotográfico e no contato com a pesquisa); na construção do sentimento de pertença destes agentes em seus grupos familiares e sociais - deslocamentos, práticas religiosas e cívicas, a composição de uma memória familiar entro outros recortes de lembranças (SCHAPOCHNIK, 1998, p. 463).

Essas fotografias não permanecem apenas em arquivos de famílias. Devido a sua natureza, e pelo contexto de produção, em sua maioria, cumprem o papel de ex-votos. Assim, a Sala de Promessas é o local reservado de muitas das imagens e histórias citadas neste estudo. Um espaço destinado ao depósito dos ex-votos (muletas, cabeças e corpos em miniaturas esculpidos em madeira ou em cera, tufos de

modalidade variava de romeiro para romeiro, de acordo com o nível de importância que o pedido tinha em sua vida. 
LOPES, André Camargo; BARBOSA, Carlos Alberto Sampaio. Fotografias na praça: a produção e os usos das fotografias de atestação nos ex-votos de romeiros em Aparecida (SP) entre as décadas de 1940-1980. Domínios da imagem, v. 13, n. 25, p.4064, jul./dez. 2019.

cabelo, vestimentas, caixas de remédios e fotografias, entre outros itens) e, nesse sentido, um depositário de intenções, de fragmentos da vida dos devotos, materializados na atestação do vínculo com o santo. E os objetos ali colocados, como constatado também por Martins (2009), estão impregnados de significados, narram histórias, pois, ao mesmo tempo em que demonstram sofrimento, revelam o agradecimento e a alegria para com a graça alcançada, revigorando a relação entre santo e devoto, por avivarem o seu poder intercessor, e, por conseguinte, promoverem a manutenção das representações a respeito do espaço.

Assim, em seu uso devocional, a fotografia assume diante do sagrado a condição de ex-voto, a de um elemento que transita entre a Sala de Promessas do Santuário e o álbum de memórias de família. As representações contidas na imagem fotográfica constituem em sua materialidade indícios de um conjunto de práticas que se dinamizam na multiplicidade de intenções de seus agentes.

O advento da fotografia como ícone e como ex-voto sugere uma mudança no imaginário religioso, reflete a redução da fé ao imaginário de um real supostamente sem ocultações, sem invisibilidades, sem demônios (MARTINS, 2009, p. 77).

Também por seus custos, a fotografia se converteu no principal elemento de comprovação do milagre, substituindo as rústicas esculturas de partes de corpos, reproduzidas em madeira, barro ou cera, o que antes restava como opção às pessoas com menos recursos financeiros visto que a pintura, outra forma de representação nesta prática, restringia-se ao uso de poucos?

7 O tema pode ser melhor apreciado em BARROS, José Márcio. Cultura, Memória e Identidade: Contribuições ao Debate. Cadernos de História, Belo Horizonte, v.4, n.5, dez./99. 
LOPES, André Camargo; BARBOSA, Carlos Alberto Sampaio. Fotografias na praça: a produção e os usos das fotografias de atestação nos ex-votos de romeiros em Aparecida (SP) entre as décadas de 1940-1980. Domínios da imagem, v. 13, n. 25, p.4064, jul./dez. 2019.

A organização e os usos da imagem, em muitas situações, se assemelham a tábuas votivas, ou aos quadros de milagres, painéis pintados a óleo sobre madeira, divididos em três partes: a legenda, situada na parte inferior, que ocupa toda a largura do quadro e testemunha o poder miraculoso do santo face à solicitação do crente; a zona terrena, no meio do quadro, na qual se faz a representação do milagre; e a zona celestial, na parte superior, onde se representa a divindade interveniente no milagre, ocupando toda a largura do painel ou apenas um dos cantos.

Imagem 7 - Armário com fotografia de crianças e brinquedos na Sala de Promessas na Basílica Nova de Aparecida - Aparecida (SP), 2014. - Fotógrafo: André Camargo Lopes.

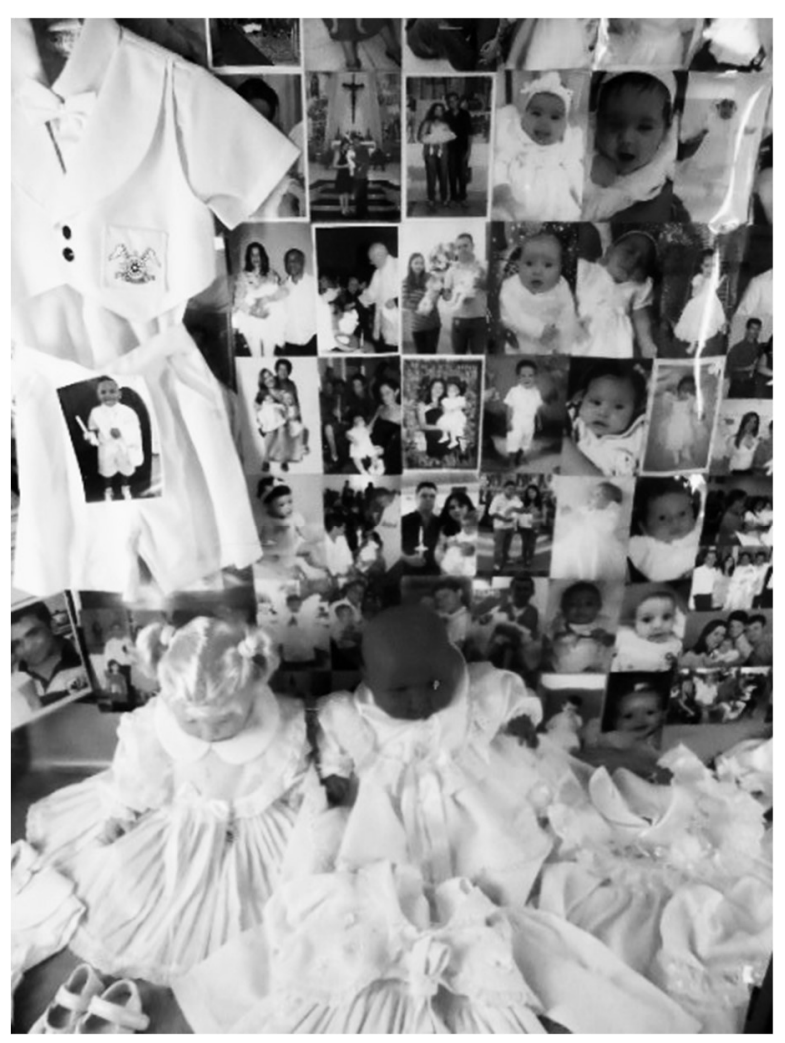

Fonte: Acervo André Camargo Lopes. 
LOPES, André Camargo; BARBOSA, Carlos Alberto Sampaio. Fotografias na praça: a produção e os usos das fotografias de atestação nos ex-votos de romeiros em Aparecida (SP) entre as décadas de 1940-1980. Domínios da imagem, v. 13, n. 25, p.4064, jul./dez. 2019.

Esta divisão compositiva é observável também em muitas fotografias. Respeitadas as diferenças entre as linguagens: famílias inteiras a posarem frente à figura da santa, que não é encoberta, mas que aparece entre eles como um ser vivificado. Na imagem anterior, a santa é postada como um membro da família, pertencente à história que se pretende narrar. Não é apenas o espaço que remete à devoção ou à promessa, mas todos os elementos envolvidos passam a compor a imagem, materializando as relações.

Imagem 8 - Proprietária: Irene Vieira (década de 1960)

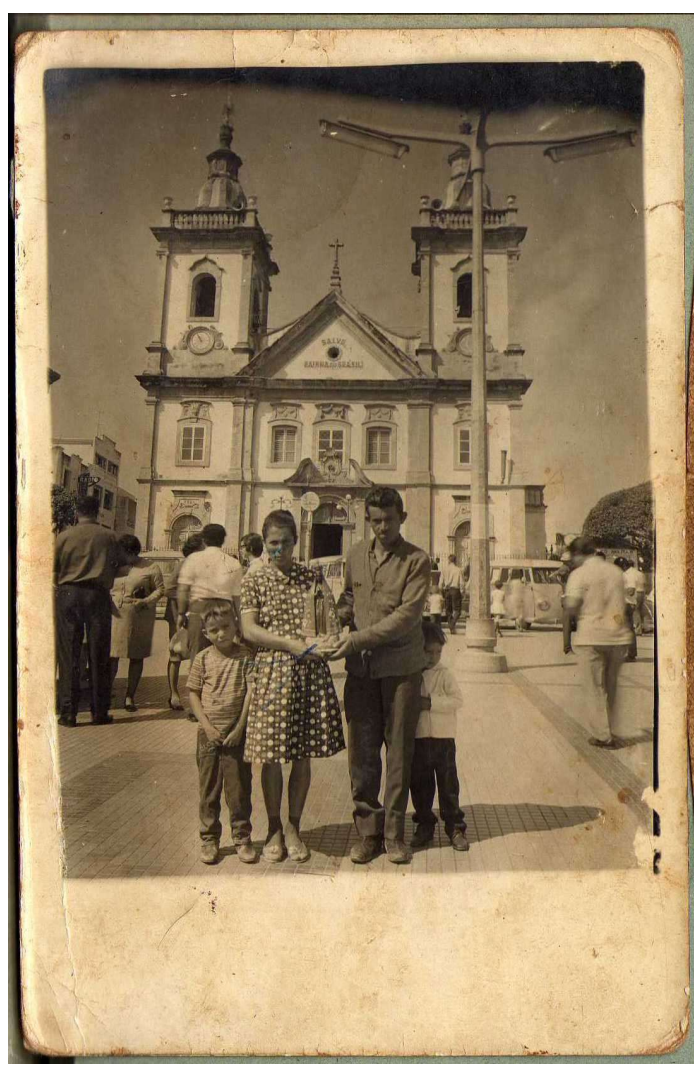

Acervo: André Camargo Lopes/ projeto Clube da Fotografia

Este imaginário fotográfico é reforçado pelas anotações no verso, narrando o milagre, entre outros elementos. A imagem é então um produto da prática de fé popular, pois, não institucionalizada e inserida na tradição presente nos espaços do Santuário. A condição do devoto, de agente ativo, promove uma junção de histórias que se entrecruzam 
LOPES, André Camargo; BARBOSA, Carlos Alberto Sampaio. Fotografias na praça: a produção e os usos das fotografias de atestação nos ex-votos de romeiros em Aparecida (SP) entre as décadas de 1940-1980. Domínios da imagem, v. 13, n. 25, p.4064, jul./dez. 2019.

na ação devocional, e que reavivam e dão visibilidade às suas concepções rituais, saturando o espaço com um fragmento de seu universo social.

\section{Romeiros, romarias e promessas}

O uso da fotografia como ex-voto ou lembrança de viagem ao Santuário, numa perspectiva histórica, possibilitou o desenvolvimento de uma rede de sociabilidade baseada na comercialização da imagem, com seu período de ápice e decadência.

Esse comércio, de acordo com Jesus (2006), se estabeleceu associado a um universo mais amplo de negociação (desde bens simbólicos como rosários até a rede de hotelaria e hospedagens). Para o autor, a aquisição de algum artigo significa para o devoto o trazer para a sua residência um prolongamento da presença da sacralidade em seu cotidiano. Logo, as "Fotografias de Aparecida" revelam muito mais do que as práticas devocionais. Estas manifestam um universo cultural, um imaginário que estabelece, e se constitui em, uma rede produtora de bens simbólicos, paralela ao discurso oficial. O que se tem é um diálogo entre o imaginário popular e o espaço sagrado, sendo as imagens 0 produto resultante deste contato de "adaptabilidades".

Na fotografia 9, centenas de pessoas se movimentam pelo estacionamento reservados aos ônibus de romeiros que, semanalmente, visitam o Santuário. São pessoas de origem distintas, todavia com visões de mundo confluentes muitas vezes apenas na devoção a Nossa Senhora Aparecida. 
LOPES, André Camargo; BARBOSA, Carlos Alberto Sampaio. Fotografias na praça: a produção e os usos das fotografias de atestação nos ex-votos de romeiros em Aparecida (SP) entre as décadas de 1940-1980. Domínios da imagem, v. 13, n. 25, p.4064, jul./dez. 2019.

Imagem 9 - Movimentação de romeiros em 1961. Organização: João Bosco Garcia

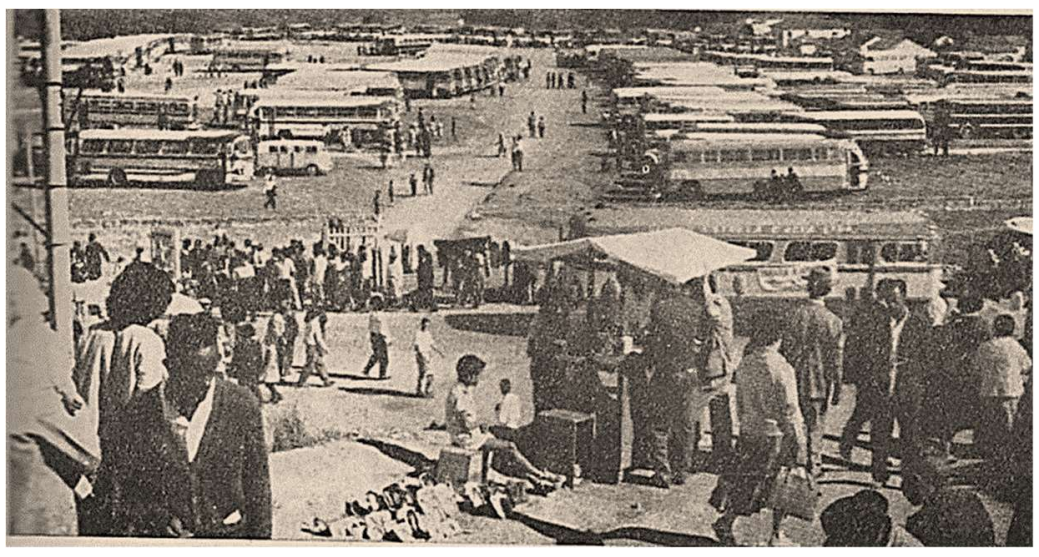

Acervo: Jornal Tranca e Gamela

A presença do "outro" (ou estrangeiro) no espaço, gera percepções diversas e estranhamentos entre todas as partes, como o descrito no texto abaixo:

Em minha infância tive pessoas que me ensinaram a amar Jesus. Mamãe foi uma delas.

Além dos momentos de oração e atitudes de amor, mamãe incentivava os filhos as participarem da igreja.

Íamos sempre à reza. Naquele tempo havia reza na Basílica Velha. Cida, minha irmã, cantava no coro. Havia terços, pregação, cantos e benção do Santíssimo.

Sentávamos quase sempre no mesmo banco.

Enquanto um padre redentorista presidia a celebração, intercalada pelo som do órgão e canto do coral, eu, criança observadora, prestava atenção nas pessoas que estavam ao lado.

Lembro-me dos romeiros que naquela época eram diferentes. Eram pessoas muito simples. Sentavam-se nos degraus das colunas quando os bancos estavam tomados. Às vezes a família toda vestia o mesmo tecido. Sinto até o cheiro deles... Não chegava a ser mau cheiro ou suor. Acho que era cheiro de fumaça. Os homens também tinham cheiro de cigarro de palha. As crianças eram quietas e apáticas. Muitas dormiam no colo ou no chão. As mães muitas vezes amamentavam os filhos ali mesmo.

No frio, os homens usavam 'pelerine' - capas de vaqueiros que compravam nas lojas dos turcos ${ }^{8}$. [grifo meu]

8 Esse trecho pertence a uma seção de memórias do jornal local "Tranca e Gamela". Trata-se da seção "Histórias que eu conto e canto", com a finalidade de manter viva a 
LOPES, André Camargo; BARBOSA, Carlos Alberto Sampaio. Fotografias na praça: a produção e os usos das fotografias de atestação nos ex-votos de romeiros em Aparecida (SP) entre as décadas de 1940-1980. Domínios da imagem, v. 13, n. 25, p.4064, jul./dez. 2019.

"Eram pessoas muito simples", ou "Não chegava a ser mau cheiro", ambas as colocações da autora, remetem a uma leitura local do outro, nesse caso, o romeiro. São memórias de infância, descritas pela professora Margarida Thereza de Menezes Reis, a leitura do estabelecido em relação ao "outro" na perspectiva do cotidiano rompido pelo cheiro, pela apatia, roupas e comportamento. A memória narrada no texto refere-se à manutenção da tradição familiar, católica, educada dentro da igreja e de seus cânones. Assim, percebe-se neste, e em alguns outros textos do jornal9, memórias de um conservantismo cultural, flexibilizado pela presença do outro (o romeiro) ${ }^{10}$.

Este aspecto da flexibilização inter-relacional entre os locais e os romeiros de Aparecida, que não se limita ao espaço em questão, foi constatado por Cordeiro (2010, p. 73) em seu estudo sobre Juazeiro do Norte. A autora, ao descrever o trânsito dos romeiros, procurou situá-los na trama constitutiva do espaço. Em sua análise estes estariam em uma

memória de Aparecida, por meio de histórias narradas por seus moradores. O texto em questão é um fragmento das memórias narrada por Margarida Thereza de Menezes Reis. Foi publicado na edição de 30 de julho de 2004, nº 6. O jornal foi lançado em 15 de maio de 2004, como projeto do Jornalista Renato Correia Ribeiro.

$9 \mathrm{Na}$ edição de 30 de junho de 2004, n 4, pág. 3, escreveu Luiz Affonso de Freitas "Cidadania, o problema de Aparecida". No editorial de 15 de outubro de 2005, n 39, "O significado da vida: O caminho da fé".

10 Essa presença dos diferentes em um mesmo espaço social caracteriza-se como um grande desafio no campo da análise cultural. Segundo Barros, esta questão se refere a "(...) sujeitos e grupos que resistem e sobrevivem fechados sobre si próprios, desenvolvendo mecanismos de controle e reprodução de seus sistemas de representações, esquivando-se do contato com os diferentes, através de visões fortemente etnocêntricas, desenvolvendo uma postura de recusa a mudança" (BARROS, 1999, p. 33). Em Aparecida, mesmo não refletindo o rigor dos grupos estudados por Barros, o tema do conservantismo social, na ação cotidiana expressa nos textos dos jornais locais, nas revistas diocesanas e nas falas dos indivíduos entrevistados, tornou-se um mecanismo básico, manifesto nos elementos simbólicos que estruturam a rotina diária do indivíduo e do grupo, consolidando-se como um trabalho "no tempo e sobre o tempo", ressignificando o cotidiano dentro de uma lógica reprodutivista, na qual o indivíduo tende a construir padrões identitários por meio de práticas que possibilitam a permanência de valores consagrados em costumes que os normatizam, e que, em vista da sua dinâmica irreflexiva, aparentam manterem em sua disposição espaço/tempo numa inércia configurativa. A continuidade desses valores se amolda ao presente implícita ou abertamente - como parte integrante das representações, estabelecendo dentro do grupo, mecanismos de pertencimento ou exclusão. 
LOPES, André Camargo; BARBOSA, Carlos Alberto Sampaio. Fotografias na praça: a produção e os usos das fotografias de atestação nos ex-votos de romeiros em Aparecida (SP) entre as décadas de 1940-1980. Domínios da imagem, v. 13, n. 25, p.4064, jul./dez. 2019.

situação de "dentro-fora", pois tanto são responsáveis pelos fluxos migratórios, formadores do município, e que "(...) conhecidos (...) pela repetição ritual da prática estabeleceram contato com os autóctones e moradores com quem constroem espaços de proximidade", como são ao mesmo tempo "estrangeiros" que visitam anualmente a cidade. Essa relação gera outro fator decisivo nas ações cotidianas que constituem a identidade devocional estruturadora do imaginário relativo à cidade.

Tal fator se refere ao caso de essa identidade ser construída por meio de uma ação presencial compartilhada, na qual o elemento subjetivo coexiste com o coletivo, em um processo de reciprocidade - são as práticas dos muitos segmentos devocionais que legitimam a religiosidade a Nossa Senhora Aparecida. Por meio deste contato, o indivíduo define com o outro (coletivo ou individual), uma relação de elementos significantes, e, nesse sentido, o imaginário social constituído transcende a condição da localidade. No processo de interação, os padrões de sociabilidade se flexibilizam ${ }^{11}$.

No mesmo sentido, a descrição dos romeiros, na narrativa da professora Margarida Thereza de Menezes Reis, foca na definição "(...) Lembro-me dos romeiros que naquela época eram diferentes. Eram pessoas muito simples", o que em uma perspectiva histórica, situam-nos no perfil social, descrito por Brustoloni (1979), em sua maioria, homens simples, ou os homens rústicos de Zaluar (1983). Indivíduos que teriam desaparecido gradualmente no trânsito social das comunidades rurais para o espaço urbano. O romeiro "diferente" problematizado no trecho acima reflete as transformações nas práticas e hábitos tradicionais. A devoção espontânea, ou a sua prática, foi aos poucos absorvida pela sistematização devocional da Igreja Católica, e com isso os símbolos e os

11 Existe na compreensão dessa estruturação simbólica, uma inter-relação entre o espaço, as instituições e os homens. Em Aparecida isto é evidenciado nas mídias que divulgam a cidade, na expansão hoteleira, na sacralização dos espaços e na política pública de tratamento ao romeiro. 
LOPES, André Camargo; BARBOSA, Carlos Alberto Sampaio. Fotografias na praça: a produção e os usos das fotografias de atestação nos ex-votos de romeiros em Aparecida (SP) entre as décadas de 1940-1980. Domínios da imagem, v. 13, n. 25, p.4064, jul./dez. 2019.

rituais foram adequados a um universo ordeiro e centralizador. $\mathrm{Na}$ prática, isso significa mudanças profundas na compreensão de mundo.

(...) Nas cidades, também as festas realizadas para homenagear determinados santos de devoção local deixavam de seguir as normas costumeiras: o grupo de músicos devotos do santo (folia) não percorria a região circunvizinha recolhendo dádivas para o repasto coletivo e a distribuição gratuita da comida, os quais estavam sendo substituídos por barraquinhas vendendo "comes e bebes" e pelo leilão de prendas. Não havia mais bailes e folguedos que eram violentamente criticados por padres e por aqueles que compartilhavam sua doutrina, os quais viam nesses eventos uma profanação da solenidade sagrada. (...) E por fim, as promessas que eram sempre feitas em função das festas tradicionais, pareciam estar mudando de caráter: no contexto urbano, falava-se mais do uso do ex-voto e nas romarias feitas às cidades santuários para pagar promessas. (ZALUAR, 1983, p. 15) ${ }^{12}$

A transposição desse imaginário religioso católico popular, que tende ao coletivo, é substituída por uma lógica individualizadora da promessa cumprida em romaria. As romarias como fenômeno social, cumprem um duplo papel, ao mesmo tempo em que reforçam o controle da Igreja sobre os espaços e os santos de devoção, refletem uma forma de organização popular da fé. De acordo com Cordeiro (2010), o fenômeno social da romaria está diretamente ligado a três aspectos: o religioso, o econômico e o político. Em sua análise, esses elementos são indissociáveis, correspondem à base de inteligibilidade das romarias.

Em sua Tese, Moreno (2009, p.94) constata essa mudança no perfil social do romeiro. Em relação ao tipo de transporte utilizado por estes, afirma o autor, percebe-se, um crescimento significativo no número de

\footnotetext{
12 Sobre essa transformação nos aspectos sociais, e o consequente impacto na rotina cultural dos indivíduos, o texto citado de Alba Zaluar (1983)é pontual, datado em um recorte temporal que se estende de 1940 a 1953, período que corresponde à transição de um modelo de organização social rural para o crescente plano urbano no país.
} 
LOPES, André Camargo; BARBOSA, Carlos Alberto Sampaio. Fotografias na praça: a produção e os usos das fotografias de atestação nos ex-votos de romeiros em Aparecida (SP) entre as décadas de 1940-1980. Domínios da imagem, v. 13, n. 25, p.4064, jul./dez. 2019.

"carros de passeio". Historicamente, este aspecto de transformação reflete a heterogeneidade do perfil social apontado pelo fotógrafo ${ }^{13}$.

A compreensão da cidade de Aparecida como um Santuário exige do devoto que se desloque do seu cotidiano como manifestação de fé. No imaginário popular, rumar-se para aquele espaço é uma forma de provar a sua devoção. É uma reorientação da prática devocional que determina um distanciamento de lugares e universos familiares. Essa experiência refletiria uma renovação espiritual e de estímulo à pertença católica.

Nesse sentido, o deslocamento para a cidade como manutenção de um imaginário devocional católico pode ser cotejado pela definição de espaço sagrado proposta por Eliade, visto que para o autor, o homem religioso não entende o espaço como algo homogêneo, pelo contrário, "(...) o espaço apresenta roturas, quebras; há porções de espaços qualitativamente diferentes das outras. (...) Há, portanto, um espaço sagrado, e, por consequência, forte, significativo; e há outros espaços

\footnotetext{
13 Até 1920, os romeiros vinham em grupos, a pé ou em carros de boi. Desse modo, a mudança não foi abrupta, pois, ainda no século XIX, com a inauguração da Estrada de Ferro Rio-São Paulo, em 1877, o transporte ferroviário passou a ser utilizado em larga escala por romeiros da região. Em 1900, começaram a serem organizadas romarias programadas pela própria lgreja, utilizando-se de comboios especiais fornecidos pela Central do Brasil (MORENO, 2009). Esse aspecto transformador das vias de acesso à cidade também está registrado no texto de Brulostoni: "(...) Hoje as romarias se fazem de outro modo, desde que a Estrada do Norte desdobrou as suas paralelas de aço pelo Vale do Paraíba, e pousou suas estações onde eram antigamente o pouso dos viajantes, tudo mudou. Há mais comodidade de transporte, mas também acabou-se o encanto daquelas pias viagens. (...) A maior parte dos romeiros vem de trem, mas no tempo seco, de abril a novembro, vem muitas caravanas com 15 até 30 cavalos, burros e cargueiros" (1979, p. 110). O autor cita, em um primeiro momento, um artigo publicado em 04 de janeiro de 1884, no Jornal Correio Paulistano, sob o título "Fia-te na viagem", referindo-se ao impacto da estrada de ferro nos hábitos dos romeiros. O segundo trecho de citação corresponde a uma carta do Padre Lourenço Gahr ao seu amigo Monsenhor Bachar, em Bremen, na Alemanha. Nessa carta, datada de 01 de junho de 1895, procurou descrever o formato dessas romarias. Ambos os trechos demonstram 0 impacto da via férrea, porém, a permanência (no primeiro numa ação de saudosismo), dos antigos hábitos de transporte. Após 1920, com a melhoria da malha viária de acesso à região, intensificou-se o uso de automóveis, ônibus e caminhões jardineira. Todavia, de acordo com Brustoloni (1979), o uso do trem se estendeu oficialmente até 1954.
} 
LOPES, André Camargo; BARBOSA, Carlos Alberto Sampaio. Fotografias na praça: a produção e os usos das fotografias de atestação nos ex-votos de romeiros em Aparecida (SP) entre as décadas de 1940-1980. Domínios da imagem, v. 13, n. 25, p.4064, jul./dez. 2019.

não sagrados, sem estruturas, nem consistência, em suma amorfos" (2001, p.25-26).

O espaço sagrado, tal como definiu Eliade (2001), constitui-se na ruptura deste com a totalidade do espaço, áreas diferenciadas, criadas pela própria intenção do agente, o centro de um mundo que legitima a ação, e que, pensado no quadro apresentado por Cordeiro (2010), incide sobre o imaginário religioso.

Mesmo sendo uma ação que predominantemente se desenvolve pela vontade popular, a romaria destoa da concepção tradicional santo-devoto (festas, novenas, folias e peditórios). Esse fenômeno social se caracteriza a grosso modo, por seu viés penitencial e não festivo. Retomando Zaluar (1983), entende-se que a massificação da preferência devocional pela prática da romaria e pela penitência como manifestação de fé e devoção, revela uma nova ética religiosa dotada de preconceitos morais advindos de transformações sociais, culturais e na estrutura organizacional do catolicismo brasileiro. De acordo com a autora, a romaria é o oposto à festa que tem o divertimento como um dos centros da celebração. A romaria tende a ser a própria penitência da promessa, um sacrifício, um oferecimento da própria pessoa ao santo.

\section{Considerações finais}

A compreensão das "Fotografias de Aparecida" está diretamente relacionada à relação entre promessa e milagre. A promessa é um elemento significativo para entendimento do impulso gerador no deslocamento do devoto ao Santuário.

Pautada na reciprocidade como prática de manutenção dos vínculos entre o santo e o devoto, a promessa se baseia em prestações e contraprestações estabelecidas. A relação devocional no imaginário 
LOPES, André Camargo; BARBOSA, Carlos Alberto Sampaio. Fotografias na praça: a produção e os usos das fotografias de atestação nos ex-votos de romeiros em Aparecida (SP) entre as décadas de 1940-1980. Domínios da imagem, v. 13, n. 25, p.4064, jul./dez. 2019.

do catolicismo popular funda-se no princípio que este contato tem um significante imediato e concreto da ação comunicativa.

Ao adotar a linha reflexiva acerca do imaginário social, entendo esses processos como formas de construção, inseridas na realidade cotidiana do indivíduo, em seus espaços tanto o doméstico como o social, e reforçadas por uma rotina de ações concretas e abstratas, que emanam de aspirações, temores, e necessidades imediatas (proteção, objetivos a serem alcançados, curas etc.).

Esta relação de reciprocidade, que constitui a relação de devoção, envolve os indivíduos e "santos", sentimentos marcados pela fé, pela confiança e pela amizade.

Nesse aspecto, um devoto tem fé em seu santo de devoção, confia que receberá a sua ajuda, e o considera um amigo. E a fotografia nesta relação atesta a ação de ambos.

\section{Referência}

BACZKO, Bronislaw. A Imaginação Social. Enciclopédia EINAUDI. Vol. 5. Lisboa/Portugal: Imprensa Nacional - Casa da Moeda, 1985.

BARROS, José Márcio. Cultura, Memória e Identidade: Contribuições ao Debate. Cadernos de História, Belo Horizonte, v.4, n.5, dez./99.

BRUSTOLONI, Pe. Júlio. A Senhora da Conceição Aparecida: História da Imagem, da Capela e das Romarias. Aparecida: Editora Santuário, 1979.

CORDEIRO, Maria Paula Jacinto. Entre chegadas e partidas: dinâmicas das romarias em Juazeiro do Norte. 2010, Tese (Doutorado em Sociologia) Universidade Federal do Ceará: Fortaleza.

CALVELLI, Haudrey G. A "Santiago de Compostela" brasileira: Religião, turismo e consumo na peregrinação pelo Caminho da Fé. 2006, Tese (Doutorado em Ciências da Religião) Universidade Federal de Juiz de Fora: Juiz de Fora, MG.

ELIADE, Mircea. O Sagrado e o Profano: a essência das religiōes. São Paulo: Edições Livros do Brasil, 2001. 
LOPES, André Camargo; BARBOSA, Carlos Alberto Sampaio. Fotografias na praça: a produção e os usos das fotografias de atestação nos ex-votos de romeiros em Aparecida (SP) entre as décadas de 1940-1980. Domínios da imagem, v. 13, n. 25, p.4064, jul./dez. 2019.

JESUS, Elivaldo Souza de. Gente de promessa, reza e romaria: experiências devocionais na ruralidade do Recôncavo Sul da Bahia (1940-1980). 2006, Dissertação (Mestrado em História). Universidade Federal da Bahia: Salvador.

MARTINS, José de S. Sociologia da Fotografia e da Imagem. São Paulo, Contexto, 2009.

MENESES, Ulpiano T. Bezerra. Memória e cultura material: documentos pessoais no espaço público. Seminário Internacional sobre Arquivos Pessoais, Rio/São Paulo, CPDOC/FGV-IEB/USP, 1997.

MENESES, Ulpiano T. Bezerra. Rumo a uma "História Visual". O imaginário poético nas Ciências Sociais. orgs. José de Souza Martins, Cornelia Eckert e Sylvia Caiuby Novaes. Bauru -SP, EdusC, 2005.

MENEZES, Renata de Castro. A Dinâmica do Sagrado: Rituais, Sociabilidade e Santidade num Convento do Rio de Janeiro. Rio de Janeiro: Relume Dumaré / UFRJ, 2004.

MORENO, Júlio César. A ação do Santuário Nacional de Aparecida e o fomento do Turismo Religioso. 2009, Tese (Ciências da Comunicação). São Paulo: Universidade de São Paulo.

SCHAPOCHNIK, Nelson. Cartões-postais, Álbuns de Família e Ícones da Intimidade. In: História da Vida Privada no Brasil volume 3 / coordenador geral da coleção Fernando de Novais; organização do volume Nicolau Sevchenko. São Paulo: Companhia das Letras, 1998.

SEGALA, Lygia. Fotógrafos e retratos de romeiros no Santuário Nacional de Aparecida. MHN. Rio de Janeiro: Museu Histórico Nacional Biblioteca Virtual, volume 32, 2000.

ZALUAR, Alba. Os Homens de Deus: um estudo dos santos e das festas no catolicismo popular. Rio de Janeiro: Zahar Editores, 1983. 